\title{
Comparing cost of intravenous infusion and subcutaneous biologics in COVID-19 pandemic care pathways - A brief UK stakeholder
}

\section{survey}

\author{
Adrian Heald ${ }^{1}$, Steven Bramham-Jones ${ }^{2}$, and Mark Davies ${ }^{3}$ \\ ${ }^{1}$ Salford Royal Hospitals NHS Trust \\ ${ }^{2}$ Res Consortium \\ ${ }^{3}$ Affiliation not available
}

February 19, 2021

\begin{abstract}
Objectives One important group of people at higher risk from the COVID-19 pandemic are those with autoimmune conditions including rheumatoid arthritis/inflammatory bowel disease. To minimise infection risk, many people are now being switched from intravenous to subcutaneous biologics including biosimilars. A key question is how transition costs are viewed by clinicians. Design The survey was designed to understand the comparative economic issues related to the intravenous infusion vs subcutaneous biologic administration routes for infliximab. The survey focused on direct cost drivers/indirect cost drivers. Wider policy implications linked to the pandemic were also explored. Setting/Participants Semi structured telephone interviews were carried out with twenty key stakeholders across the NHS from clinical/pharmacy/commissioning roles. The interviews were undertaken virtually 5thApril-27thApril 2020 and included a semi-structured interview framework with questions across the two administration routes. Results From interview results a simple cost analysis was developed plus a qualitative analysis of reports on wider policy/patient impacts. Key findings included evidence of significant variation in infusion tariffs UK wide, with interviewees reporting that not all actual costs incurred are captured in published tariff costs. A cost analysis showed administration costs $50 \%$ that of infusion, with a most patients administering subcutaneous medicines themselves. Other indirect benefits to this route included less pressure on infusion unit waiting times and reduced risk of COVID-19 infection plus reduced patient costs. However, this was to some extent offset by increased pressure on home-care and community/primary care services. Conclusions Switching from infusion to subcutaneous routes is currently being driven by the COVID-19 pandemic in many services. A case for biologics (infusion vs subcutaneous) must be made on accurate real-world economic analysis. In an analysis of direct/indirect costs, excluding medicine acquisition costs, subcutaneous administration appears to be the more cost saving option for many patients even without the benefit of industry funded home-care.
\end{abstract}

\section{Hosted file}

CTHC.CostPaper_11 Feb 2021.docx available at https://authorea.com/users/312300/articles/ 509807-comparing-cost-of-intravenous-infusion-and-subcutaneous-biologics-in-covid-19pandemic-care-pathways-a-brief-uk-stakeholder-survey

\section{Hosted file}

CTHC cost paper Tables.docx available at https://authorea.com/users/312300/articles/509807comparing-cost-of-intravenous-infusion-and-subcutaneous-biologics-in-covid-19-pandemiccare-pathways-a-brief-uk-stakeholder-survey

\section{Hosted file}


Costs paper Fig 1.docx available at https://authorea.com/users/312300/articles/509807comparing-cost-of-intravenous-infusion-and-subcutaneous-biologics-in-covid-19-pandemiccare-pathways-a-brief-uk-stakeholder-survey

\section{Hosted file}

Costs paper Figure 2.docx available at https://authorea.com/users/312300/articles/509807comparing-cost-of-intravenous-infusion-and-subcutaneous-biologics-in-covid-19-pandemiccare-pathways-a-brief-uk-stakeholder-survey

\section{Hosted file}

Costs paper Figure 3 2.docx available at https://authorea.com/users/312300/articles/509807comparing-cost-of-intravenous-infusion-and-subcutaneous-biologics-in-covid-19-pandemiccare-pathways-a-brief-uk-stakeholder-survey 